\title{
Relationship between Inflammation-Related Markers in Peri-Implant Crevicular Fluid and Clinical Parameters in Partially Edentulous Saudi Arabian Diabetic Subjects
}

\author{
Shaden Aljabr ${ }^{1}$, Mansoor Assery ${ }^{2}$, Sami Shafik ${ }^{3}$, Naghshbandi Jafar ${ }^{4}$, \\ Nasser Al-Daghri ${ }^{5}$, Osama Amer ${ }^{5}$ and Khalid Al-Hezaimi ${ }^{6 *}$ \\ ${ }^{1}$ Postgraduate Student, Riyadh Elm University, Riyadh, Saudi Arabia \\ ${ }^{2}$ Associate Professor, Vice Rector, Riyadh Elm University, Riyadh, Saudi Arabia \\ ${ }^{3}$ Professor of Periodontics, Dental School, Riyadh Elm University, Riyadh, Saudi Arabia \\ ${ }^{4}$ Head of Periodontology Department, School of Dentistry, Tishk International Univer- \\ sity, Erbil-Kurdistan, Iraq \\ ${ }^{5}$ Chair for Biomarkers of Chronic Diseases, College of Science, King Saud University, \\ Riyadh, Saudi Arabia \\ ${ }^{6}$ Professor, Endodontics \& Periodontics Department, School of Dentistry, Riyadh Elm \\ University, Riyadh, Saudi Arabia. \\ *Corresponding Author: Khalid Al-Hezaimi, Professor, Endodontics \& Periodontics \\ Department, School of Dentistry, Riyadh Elm University, Riyadh, Saudi Arabia.
}

Received: May 18, 2020

Published: June 18, 2020

(C) All rights are reserved by Fahad

Alshammari., et al.

\begin{abstract}
Introduction: A high prevalence of diabetes mellitus and dental caries in Saudi Arabian population is overwhelmingly reported. The aim of the study was to assess the following: 1) clinical findings of PD, BOP, and amount of keratinized tissue present around dental implant and 2) PICF levels of IL-1 $\alpha$, IL-1 $\beta$, IL-6, and IL-8 in diabetic and non-diabetic partially edentulous Saudi Arabian subjects. Materials and Methods: Total of 32 partially edentulous subjects, 16 diabetic and 16 non-diabetic, were included in the study. PICF samples were taken from peri-implant sulcus using paper point and PCR essays for IL-1 $\alpha$, IL-1 $\beta$, IL-6, and IL- 8 was performed. Clinical parameters of peri-implant PD, BOP and amount of keratinized tissue were recorded.

Results: Diabetic subjects had more significant BOP than non-diabetic counterparts $(\mathrm{p}-<0.001)$. No significant difference was found between diabetic and non-diabetic patients in the amount of keratinized tissue $(\mathrm{P}<0.765)$. A significant high level of IL-6 in diabetic subjects when compared to healthy subjects $(\mathrm{P}<0.033)$. No significant difference between diabetic and non-diabetic subjects in the serum level of IL-1 $\alpha(\mathrm{P}<0.121)$, IL-1 $\beta(\mathrm{P}<0.171)$ and IL-8 $(\mathrm{P}<0.223)$. A positive correlation between increased serum level of IL-1 $\alpha$, IL-1 $\beta$, IL-6 and IL-8 with increased PD was determined.

Conclusion: PD, BOP and PICF IL-6 levels were found to be significantly higher in Saudi Arabian diabetic subjects compared to Saudi non-diabetic subjects. Also, a positive relation found between deep PD and four inflammatory markers which are IL-1 $\alpha$, IL-1 $\beta$, IL- 6 and IL-8.

Keywords: Implant; Diabetes; Peri-Implant Crevicular Fluid; IL-1 $\alpha$; IL-1 $\beta$; IL-6; IL-8; Diabetic Saudi Arabian
\end{abstract}

\section{Introduction}

Cytokines have been reported to be elevated in chronically inflamed gingival tissue, as well as in the gingival crevicular fluid from patients with periodontitis [1]. Interleukin1 (IL-1) family has a central role in triggering and perpetuating immune and inflammatory responses [2,3]. Interleukin-1 $\beta$ (IL-1 $\beta$ ) is one of the most important cytokines in osteoclast formation and bone resorption and were therefore targeted by the majority of the reviewed studies [4]. Interleukin-6 (IL-6) induces bone resorption solely in conjunction with other bone-resorbing agents [5,6]. Presence of interleukin-8 (IL-8) has shown to be highly linked to increased susceptibility to periodontitis $[6,7]$. It has also been reported that inflammatory cytokines such as IL- $1 \alpha$, IL- $1 \beta$, IL- 6 and IL-8 are present in inflamed periodontal tissue and their significant production seems to facilitate chronic leukocyte recruitment and tissue destruction [2]. Monitoring cytokines may allow us to diagnose the status of periodontal disease and patients' susceptibility to it [2]. 
Type 2 diabetics are 2.8 times more likely to have periodontal disease characterized by clinical attachment loss and 3.4 times more likely to express radiographic bone loss [8]. Hyperglycemia could be an important factor in the development of biological complications for dental implants especially in poorly controlled diabetes [9]. The peri-implant crevicular fluid (PICF) is an osmotically mediated inflammatory exudate originating from the vessels of the gingival plexus. Its composition is similar to that of the gingival crevicular fluid (GCF) by containing host-derived enzymes and their inhibitors, inflammatory mediators, host-response modifiers, and tissue breakdown products $[10,11]$.

Prevalence of diabetes mellitus type 2 (T2DM) in Saudi Arabia is $23.1 \%$ [12]. The World Health Organization has reported that the Saudi Arabia diabetes mellitus rate ranks as the second highest in the Middle East and seventh worldwide, which corresponds to 7 million of the Saudi Arabia population as diabetic and almost 3 million are pre-diabetic [13]. From indexed literature up to date, there are no published reports assessing the cytokine presence in PICF in Saudi Arabian diabetic patients.

\section{Aim of the Study}

The aim of the present study was to: 1) assess clinical findings of probing depth, bleeding on probing, and amount of present keratinized tissue around dental implants and 2) examine PICF levels of IL- $1 \alpha$, IL-1 $\beta$, IL-6, and IL-8 among diabetic and non-diabetic Saudi Arabian subjects. The research hypothesis is that diabetic and non-diabetic Saudi Arabian individuals will exhibit the same level of cytokine in the PICF.

\section{Materials and Methods \\ Ethical approval}

Ethical approval for this study was obtained from the Ethics Committee of the Research Center and the study was done in compliance with the National Institute of Health guidelines for the care and use of laboratory animals (NIH Publication \#85-23 Rev.1985). The exclusion criteria were: 1) systemic disease such as cardiovascular disorders and renal disorders, 2) systemic antibiotic or steroid intake within the last three months, 3) history of periodontal treatment within the previous 3 months, 4) radiation and/or chemo therapy during the last six months and 5) tobacco smoking. This was a parallel study design where each group has 16 subjects. The groups are: Group 1 consisted of diabetic patients and Group 2 of non-diabetic patients. Diagnosis of T2DM was confirmed by patient physician and a report of their last HA1C. Subjects voluntarily enrolled in the study and signed a written consent form.

\section{Clinical examination}

All clinical and radiographic evaluations were performed by one investigator. Intracalibration for the examiner was recorded and calculated kapa index was 0.92 . Peri-implant probing depth (PD) was measured at six sites, and those sites were mesiobuccal, midbuccal, distobuccal, distolingual, midlingual, and mesiolingual. Bleeding on probing (BOP) and amount of keratinized tissue at midfasial were measured (Table 1). Clinical examination was measured using University of North Carolina probe (UNC-15, HuFriedy, Chicago, IL, USA).

\section{Collection of peri-implant crevicular fluid samples}

All examination sites were swabbed with $2 \times 2$ sterile gauze to clean the surrounding tissue from debris. PICF samples were collected using sterile paper point \#35 (Meta Biomedm, Chungcheongbuk-do, South Korea). The sterile paper point was inserted in the peri-implant pocket and held in place for 60 seconds; then the paper point was transferred to sterile tubes containing $500 \mu \mathrm{L}$ of sterilized elution buffer $(0.05 \%$ polysorbate 20 in phosphate-buffered saline pH 7.4). Samples were subjected to centrifugation (HERMLE Labortichnik GmbH, Wehingen, Germany) at 13,000 rpm for 15 minutes.

\section{Biochemical analyses}

IL- $1 \alpha$, IL-1 $\beta$, IL- 6 and IL- 8 were measured using the Milliplex Map kit (Millipore, Billerica, MA, USA) in the FlexMAP 3D (Luminex Corp, Austin, TX, USA) according to the manufacturer's instructions. Minimum detectable concentrations were as follows: IL-6, $0.9 \mathrm{pg} / \mathrm{ml}$; IL-1 $\alpha, 9.4 \mathrm{pg} / \mathrm{ml}$; IL- $1 \beta, 0.8 \mathrm{pg} / \mathrm{ml}$; and IL-8, $0.4 \mathrm{pg} / \mathrm{ml}$. The intra-assay variation was as follows: IL-6, 2.0\%; IL-1 $\alpha, 3.3 \%$; IL-1 $\beta, 2.3 \%$; and IL-8, 1.9\%, and inter-assay variation of: IL-6, 18.3\%; IL-1 $\alpha, 12.8 \%$; IL-1 $\beta, 6.7 \%$; and IL-8, 3.5\%.

\section{Statistical analysis}

The data analysis was performed using Statistical Packages for Social Sciences (SPSS) version 21 (SPSS, Chicago, IL, USA). Descriptive statistics were presented using mean and standard deviation or counts and proportion (\%) whenever appropriate. The statistical association between the characteristics of each study group (diabetic and non-diabetic) were conducted using an independent t-test or Chi-square test whenever applicable. Binary regression analysis was also conducted to predict the influence of PD, cytokine and bleeding on probing among diabetic patients where the odds ratio as well as $95 \% \mathrm{CI}$ were also being reported. A P value of $<0.05$ was considered statistically significant and a $P$ value of $<0.01$ was considered highly statistically significant. 
Relationship between Inflammation-Related Markers in Peri-Implant Crevicular Fluid and Clinical Parameters in Partially Edentulous Saudi Arabian Diabetic Subjects

103

\section{Results}

Results show a higher and significant probing depth in diabetic group around dental implants (Table $1, \mathrm{p}<0.004$ ). BOP was the most significant clinical measurement in diabetic subjects (Table $1, p<0.001)$. There was no significant difference in the amount of keratinized tissue between diabetic and non-diabetic subjects (Table $1, \mathrm{p}<0.765$ ). PICF IL-6 was the only inflammatory marker present with significantly elevated levels in the diabetic group when compared to non-diabetic patients (Table 2, p < 0.033). All remaining cytokines had no significant difference between the two groups (Table 2, IL-1 $\alpha$ ( $p<0.121)$, IL-1 $\beta$ ( $p<0.171)$ and IL-8 ( $p<$ 0.223 , Figure 1$)$. IL- $1 \alpha$ and IL- 6 were significantly higher in subjects who had BOP (Table 3 , ( $\mathrm{p}<0.010$ ), ( $<<0.02$ ), respectively). IL-1 $\beta$ and IL-8 did not have any significant correlation with BOP. A positive significant correlation was found between PD and the following markers: IL-1 $\alpha$ ( $p<0.006)$, IL-1 $\beta$ ( $p<0.001)$, IL-6 ( $p<$ $0.018)$ and IL-8 ( $<0.002)$ (Table 4). Current results suggest a correlation between increased serum levels of IL-1 $\alpha$, IL-1 $\beta$, IL- 6 , and IL-8 with increased PD.

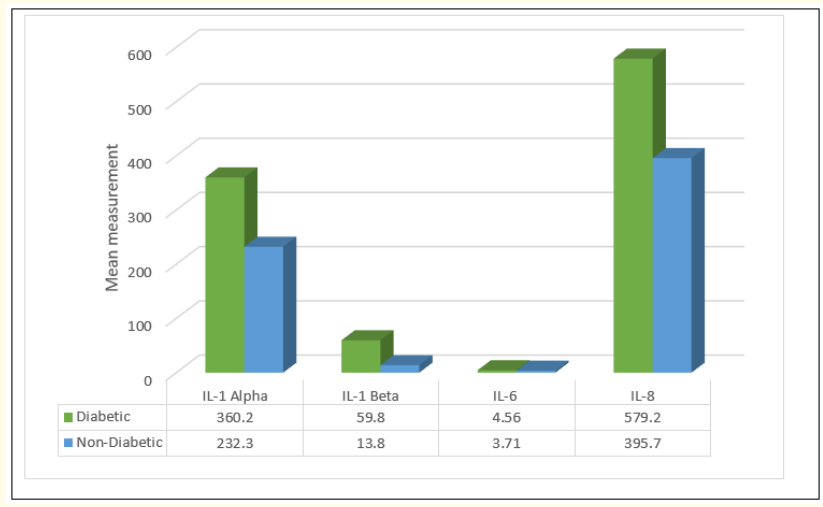

Figure 1: Mean comparison of IL-1 alpha, IL-1 beta, Il-6 and IL8 among diabetic and non-diabetic patients.

\begin{tabular}{|l|c|c|c|}
\hline \multicolumn{1}{|c|}{ Factor } & $\begin{array}{c}\text { Diabetic (n = 16) } \\
\text { Mean + SD }\end{array}$ & $\begin{array}{c}\text { Non-diabetic } \\
\text { (n= 16)Mean } \pm \text { SD }\end{array}$ & P-value \\
\hline $\begin{array}{l}\text { Keratinized tissue } \\
(\mathrm{mm})^{\mathrm{a}}\end{array}$ & $2.94 \pm 1.48$ & $2.81 \pm 0.75$ & 0.765 \\
\hline $\begin{array}{l}\text { Probing Depth } \\
(\mathrm{mm})^{\mathrm{a}}\end{array}$ & $3.09 \pm 0.66$ & $2.51 \pm 0.32$ & $0.004^{* *}$ \\
\hline $\begin{array}{l}\text { bleeding on } \\
\text { probing (\%) }\end{array}$ & $87.5 \%$ & $37.5 \%$ & $<0.001^{* *}$ \\
\hline
\end{tabular}

Table 1: Statistical association between Keratinized tissue, probing depth and bleeding on probing among diabetic and non-diabetic patients $(n=32)$.

a: P-value has been calculated using independent t-test.

b: P-value has been calculated using Fischer exact test. ** Significant at $\mathrm{p}<0.05$ level.

\begin{tabular}{|l|c|c|c|}
\hline $\begin{array}{c}\text { Cytokine } \\
\text { parameters }\end{array}$ & $\begin{array}{c}\text { Diabetic (n= 16) } \\
\text { Mean + SD }\end{array}$ & $\begin{array}{c}\text { Non-diabetic } \\
\text { (n= 16) Mean } \pm \text { SD }\end{array}$ & $\begin{array}{c}\text { P-value } \\
\S\end{array}$ \\
\hline $\mathrm{IL}-1 \alpha(\mathrm{pg} / \mathrm{mL})$ & $360.2 \pm 282.7$ & $232.3 \pm 152.2$ & 0.121 \\
\hline $\mathrm{IL}-1 \beta(\mathrm{pg} / \mathrm{mL})$ & $59.8 \pm 130.7$ & $13.8 \pm 9.61$ & 0.171 \\
\hline $\mathrm{IL}-6(\mathrm{pg} / \mathrm{mL})$ & $4.56 \pm 1.17$ & $3.71 \pm 0.95$ & $0.033^{* *}$ \\
\hline $\mathrm{IL}-8(\mathrm{pg} / \mathrm{mL})$ & $579.2 \pm 546.8$ & $395.7 \pm 220.6$ & 0.223 \\
\hline
\end{tabular}

Table 2: Statistical association between cytokine parameters among diabetic and non-diabetic patients $(n=32)$.

s: P-value has been calculated using independent t-test. **: Significant at $\mathrm{p}<0.05$ level.

\begin{tabular}{|c|c|c|}
\hline Cytokine & $\begin{array}{c}\text { Bleeding on probing }(\mathbf{n}=\mathbf{1 6}) \\
\text { Mean } \pm \text { SD }\end{array}$ & P-value $\S$ \\
\hline IL-1 $\alpha$ & $375.4 \pm 253.8$ & $0.010^{* *}$ \\
\hline IL-1 $\beta$ & $53.1 \pm 116.9$ & 0.210 \\
\hline IL-6 & $4.49 \pm 1.07$ & $0.021 * *$ \\
\hline IL-8 & $569.3 \pm 497.4$ & 0.158 \\
\hline
\end{tabular}

Table 3: Correlation between bleeding on probing and cytokine markers among diabetic and non-diabetic patients $(n=32)$.

s: P-value has been calculated using independent t-test. ** Significant at $\mathrm{p}<0.05$ level.

\begin{tabular}{|c|c|c|}
\hline Factor & PD R-value & P-value \\
\hline IL-1 $\alpha$ & 0.479 & $0.006^{* *}$ \\
\hline IL-1 $\beta$ & 0.564 & $0.001^{* *}$ \\
\hline IL-6 & 0.416 & $0.018^{*}$ \\
\hline IL-8 & 0.537 & $0.002^{* *}$ \\
\hline
\end{tabular}

Table 4: Correlation (Pearson-R) between probing depth and cytokine markers among diabetic and non-diabetic patients $(n=32)$.

$$
\begin{aligned}
& \text { **: Significant at } \mathrm{p}<0.01 \text { level (2-tailed). } \\
& \text { *: Significant at } \mathrm{p}<0.05 \text { level }(2 \text {-tailed). }
\end{aligned}
$$

\section{Discussion}

Present study showed PICF concentration of IL-6 was significantly higher in diabetic than in non-diabetic Saudi Arabian individuals. These results are consistent with previous studies [14-19]. Immunohistochemical studies have observed that a higher level of IL6 was expressed in inflamed gingival tissue than in healthy control tissue [20]. Previously published reports used a reverse transcription polymerase chain reaction (RTPCR) and ELISA to demonstrate mRNA and protein expression which have shown that IL6 serum levels were high in patients with periodontal diseases [21,22]. Also, our results confirmed the positive significant correlation between IL-6 and BOP in Saudi diabetic patients. Significant elevation of IL-6 
usually associated with peri-implantitis [23]. Diabetic patient has increased odds of increased bio gingival biofilm with increase IL-6 [24]. This could suggest close maintenance program for T2DM patients with dental implants.

In our study, PICF concentrations of IL- $1 \alpha$, IL- $1 \beta$, and IL-8 showed no significant difference between diabetic and non-diabetic Saudi Arabian patients. Others have confirmed the high overexpression and serum level of IL- $1 \alpha$, IL-1 $\beta$, and IL-8 in periodontitis patients around natural teeth [25-27]. Some factors such as subjects' ethnic background, age, gender, how well controlled their diabetes is, and the onset of diabetes may make the comparisons impossible to do between these studies $[27,28]$.

Our results confirm the correlation between elevated PICF concentrations for IL- $1 \alpha$, IL- $1 \beta$, IL- 6 and IL- 8 with increased PD. This positive correlation is a proportional one. Similar findings have been reported that the increased levels of IL- $1 \beta$ correlate positively with increasing mean of probing depth around dental implants [29]. Another study showed that increased levels of IL-6 and IL-8 are associated with chronic periodontal disease and peri-implantitis sites in patients with T2DM [30]. Because of implant platform relative to the crestal bone position may create some crestal bone loss which may favor the colonization of anaerobic gram-negative species which may be involved in triggering pro-inflammatory responses [29,31].

This study identified a correlation between elevated PICF concentrations of IL- $1 \alpha$ and IL- 6 with BOP in Saudi Arabian diabetic subjects. Similar results reported elevated concentrations of IL$1 \beta$ and IL-6 in PICF sites associated with mucositis [32]. Profuse bleeding and suppuration in untreated peri-implantitis can be associated with higher PICF concentrations of IL-1 $\beta$, IL-8, TNF-a, and VEGF [33]. IL- 6 was found to be more sensitive to the severity of the inflammation in peri-implant tissue [34]. IL-6 is one of the most investigated pro-inflammatory cytokines between healthy and diseased peri-implant tissues [34-36].

\section{Conclusion}

Up to date, there are no published report studying the cytokine presence of PICF in Saudi Arabian diabetic patients. PD, BOP and PICF IL-6 levels were found to be significantly higher in Saudi Arabian diabetic subjects compared to Saudi non-diabetic subjects. Also, a positive relation found between deep PD and four inflammatory markers which are IL- $1 \alpha$, IL-1 $\beta$, IL-6, and IL-8. The main limitation of this study was the small sample size. Future studies on the Saudi Arabian diabetic population with a larger sample size representing all different regions in Saudi Arabia. Also, it is important to investigate the impact of cytokine in PICF and its impact on the glycemic level of Saudi Arabia diabetic patients.

\section{Conflicts of Interest}

The authors have no conflicts of interest to declare.

\section{Acknowledgement}

The authors are grateful to the Chair for Biomarkers of Chronic Diseases, Deanship of Scientific Research at King Saud University (Riyadh, Saudi Arabia) for supporting this study. Also, Authors thanks Riyadh Elm University Bio laboratory for their support.

\section{Bibliography}

1. Birkedal-Hansen H. "Role of cytokines and inflammatory mediators in tissue destruction". Journal of Periodontal Research 28 (1993): 500-510.

2. Okada H and Murakami S. "Cytokine expression in periodontal health and disease". Critical Reviews in Oral Biology and Medicine 9 (1998): 248-266.

3. Kurşunlu S., et al. "Gingival crevicular fluid interleukin-36 $\beta$ $(-1 F 8)$, interleukin-36y (-1F9) and interleukin-33 (-1F11) levels in different periodontal disease". Archives of Oral Biology 60 (2015): 77-83.

4. Faot F., et al. "Can Peri-Implant Crevicular Fluid Assist in the Diagnosis of Peri-Implantitis? A Systematic Review and MetaAnalysis". Journal of Periodontology 86.5 (2015): 631-645.

5. Ishimi Y., et al. "IL 6 is produced by osteoblasts and induces bone resorption". Journal of Immunology 145 (1990): 3297 3303.

6. Uitto V., et al. "Proteolytic host cell enzymes in gingival crevice fluid”. Journal of Periodontology 31 (2000): 77-104.

7. Figueredo $\mathrm{C}$ and Gustafsson A. "Increased amounts of laminin in GCF from untreated patients with periodontitis". Journal of Clinical Periodontology 27.5 (2000): 313-318.

8. Emrich L., et al. "Periodontal disease in non-insulin dependant diabetes mellitus". Journal of Periodontology 62 (1991): 123131.

9. American Diabetes Association 2. Classification and Diagnosis of Diabetes". Diabetes Care 40.1 (2017): S11-S24. 
10. Wennström J., et al. "Oral rehabilitation with implant-supported fixed partial dentures in periodontitis-susceptible subjects". Journal of Clinical Periodontology 31 (2004): 713-724.

11. Javed F Al-Hezaimi K., et al. "Proinflammatory cytokines in the crevicular fluid of patients with peri-implantitis". Cytokine 53 (2011): 8-12.

12. Al-Daghri N., et al. "Diabetes mellitus type 2 and other chronic non-communicable diseases in the central region, Saudi Arabia (riyadh cohort 2): a decade of an epidemic". BMC Medicine 9 (2011): 76

13. Al Dawish M., et al. "Diabetes Mellitus in Saudi Arabia: A Review of the Recent Literature". Current Diabetes Reviews 12 (2016): 359.

14. Kardesxler L., et al. "Gingival crevicular fluid IL-6, tPA, PAI2 , albumin levels following initial periodontal treatment in chronic periodontitis patients with or without type 2 diabetes". Inflammation Research 60 (2011): 143-151.

15. Noh M., et al. "Assessment of IL 6, IL 8 and TNF $\alpha$ levels in the gingival tissue of patients with periodontitis". Experimental and Therapeutic Medicine (2013): 847-851.

16. Huang X., et al. "Hyperglucose contributes to periodontitis: Involvement of the NLRP3 pathway by engaging the innate immunity of oral gingival epithelium". Journal of Periodontology. 86 (2015): 327-335.

17. Shikama Y., et al. "Possible involvement of palmitate in pathogenesis of periodontitis". Journal of Cellular Physiology 230 (2015): 2981-2989.

18. Polak D and Shapira L. "An update on the evidence for pathogenic mechanisms that may link periodontitis and diabetes". Journal of Clinical Periodontology 45 (2018): 150-166.

19. Sanz M., et al. "Scientific evidence on the links between periodontal diseases and diabetes: consensus report and guidelines of the joint workshop on periodontal diseases and diabetes by the International Diabetes Federation and the European Federation of Periodontology". Journal of Clinical Periodontology 45 (2018): 138-149.

20. Bartold PM and Haynes DR. "Interleukin- 6 production by human gingival fibroblasts". Journal of Periodontal Research 26 (1991): 339-345.
21. Reinhardt R., et al. "Gingival fluid IL-1 and IL-6 levels in refractory periodontitis". Journal of Clinical Periodontology 20 (1993): 225-231.

22. Botero J., et al. "Profiling of inflammatory cytokines produced by gingival fibroblasts after human cytomegalovirus infection". Oral Microbiology and Immunology 23 (2008): 291-298.

23. Severino V0., et al. "Expression of IL-6, IL-10 IL-17 and IL-8 in the peri-implant crevicular fluid of patients with peri-implantitis". Archives of Oral Biology 56.8 (2011): 823-828.

24. Andriankaja OM., et al. "Levels of serum interleukin (IL)-6 and gingival crevicular fluid of IL-1beta and prostaglandin E (2) among non-smoking subjects with gingivitis and type 2 diabetes". Journal of Periodontology 80.2 (2009): 307-316.

25. Duarte P., et al. "Overexpression of interleukin-1beta and interleukin-6 may play an important role in periodontal breakdown in type 2 diabetic patients". Journal of Periodontal Research 42 (2007): 377-381.

26. Engebretson S., et al. "The influence of diabetes on gingival crevicular fluid beta-glucuronidase and interleukin-8". Journal of Clinical Periodontology 33 (2006): 784-790.

27. Bulut U., et al. "Interleukin-1 beta levels in gingival crevicular fluid in type 2 diabetes mellitus and adult periodontitis". The Journal of Oral Science 43 (2001): 171-177.

28. Salvi GE., et al. "Inflammatory mediator response as a potential risk marker for periodontal diseases in insulin-dependent diabetes mellitus patients". Journal of Periodontology 68 (1997): 127-135.

29. Recker E., et al. "Cross-sectional assessment of biomarker levels around implants versus natural teeth in periodontal maintenance patients". Journal of Periodontology 86.2 (2015): 264272.

30. Venza I., et al. "Proinflammatory gene expression at chronic periodontitis and peri-implantitis sites in patients with or without type 2 diabetes". Journal of Periodontology. 81 (2010): 99-108.

31. Nowzari H., et al. "The profile of inflammatory cytokines in gingival crevicular fluid around healthy osseointegrated implants". Clinical Implant Dentistry and Related Research 14 (2012): 546-552. 
32. Ata-Ali J., et al. "Clinical, microbiologic, and host response characteristics in patients with peri-implant mucositis". The International Journal of Oral and Maxillofacial Implants 28.3 (2013): 883-890.

33. Renvert S., et al. "Cytokine expression in peri-implant crevicular fluid in relation to bacterial presence". Journal of Clinical Periodontology 42.7 (2015): 697-702.

34. Ghassib I., et al. "Use of IL-1 $\beta$, IL-6, TNF- $\alpha$, and MMP-8 biomarkers to distinguish peri-implant diseases: A systematic review and meta-analysis". Clinical Implant Dentistry and Related Research 21 (2019): 190-207.

35. Meyer S., et al. "Experimental mucositis and experimental gingivitis in persons aged 70 or over. Clinical and biological responses". Clinical Oral Implants Research 28 (2017): 10051012.

36. Liu J., et al. "High mobility group box 1 protein level as a novel biomarker for the development of peri-implant disease". Scientific Reports 7 (2017): 7027.

\section{Assets from publication with us}

- Prompt Acknowledgement after receiving the article

- Thorough Double blinded peer review

- Rapid Publication

- Issue of Publication Certificate

- High visibility of your Published work

Website: www.actascientific.com/

Submit Article: www.actascientific.com/submission.php

Emaill us: editor@actascientific.com

Contact us: +91 9182824667 